The University of San Francisco

USF Scholarship: a digital repository @ Gleeson Library |

Geschke Center

\title{
Potentially Valuable Overlaps between Work System Theory, DEMO, and Enterprise Engineering
}

Steven Alter

University of San Francisco, alter@usfca.edu

Follow this and additional works at: http://repository.usfca.edu/at

Part of the Business Commons

\section{Recommended Citation}

Steven Alter. "Potentially Valuable Overlaps between Work System Theory, DEMO, and Enterprise Engineering" 1st Workshop on Enterprise Engineering Theories and Methods, at IEEE Conference on Business Informatics, Geneva, Switzerland, July 2014 (2014): 1-8.

This Conference Proceeding is brought to you for free and open access by the School of Management at USF Scholarship: a digital repository @ Gleeson Library | Geschke Center. It has been accepted for inclusion in Business Analytics and Information Systems by an authorized administrator of USF Scholarship: a digital repository @ Gleeson Library | Geschke Center. For more information, please contact repository@usfca.edu. 


\title{
Potentially Valuable Overlaps between Work System Theory, DEMO, and Enterprise Engineering
}

\author{
Steven Alter \\ School of Management \\ University of San Francisco \\ San Francisco, USA \\ alter@usfca.edu
}

\begin{abstract}
This paper explores how work system theory (WST) and related core ideas in various versions of the work system method (WSM) overlap with enterprise engineering and with the DEMO methodology. Based on the definition of work system, an enterprise can be viewed as a set of interacting work systems. A work system can be summarized at various levels of detail. The simplest level is basically a verb phrase. The next level is a "work system snapshot." More detailed descriptions are based on a work system metamodel.
\end{abstract}

This paper's contribution is in two areas, 1) establishing links between WST/WSM and enterprise engineering in general and 2) comparing aspects of WST/WSM and DEMO and demonstrating similarities, thereby implying the possibility of converting DEMO models into work system models that can be developed further using other methods and tools designed around WST. Those synergies might support combining theoretical underpinnings of DEMO with the intuitive simplicity of the work system perspective, which has been applied by many hundreds of employed MBA and Executive MBA students who produced management briefings recommending improvements in work systems in their own organizations.

The overlap between WST/WSM and DEMO is demonstrated using a DEMO representation of the OMG's EU Rent example [1], which illustrated OMG's Semantics of Business Vocabulary and Business Rules (SBVR) [2] and Business Motivation Model (BMM) [3]. A tabular summary called a work system snapshot captures much of a DEMO essential model of the EU Rent example. A more extensive summary based on a work system metamodel adds information for going from construction to implementation. The example illustrates how a work system perspective on a sociotechnical system fits with 7 postulates of an enterprise engineering manifesto [4] and with 7 enterprise engineering fundamentals [5], thereby suggesting the potential value of deeper exploration of those relationships.

Keywords - enterprise engineering, enterprise transformation, DEMO, work system, work system theory, work system method

\section{EXPLORING LINKAGES BETWEEN A WORK SYSTEM}

PERSPECTIVE, DEMO, AND ENTERPRISE ENGINEERING

This paper explores overlap between the work system method (WSM) and DEMO (Design \& Engineering Methodology for Organizations), and whether those points of overlap might be a springboard for developing new methods or techniques. WSM is a systems analysis and design method that was developed for business professionals with or without the help of technical experts. The system is a sociotechnical work system with human participants rather than an automated IT system. Although it differs from DEMO in appearance and formality, WSM was developed for similar reasons related to helping business professionals apply ideas about systems in organizations to when designing and improving those systems. It shares the goal of combining "high expressiveness with a high Return on Modeling Effort (ROME)" [1, p. 78].

Organization. The next section explains work system theory (WST), the basis of the various versions of WSM. It also summarizes a work system metamodel that extends the core ideas in WST. Next the paper shows overlaps between DEMO and WST by using a DEMO representation of the OMG's standard SBVR and BMM example involving EU Car Rental [1]. Studying the relationship between WST/WSM and DEMO could lead to new insights, methods, and techniques.

\section{WORK SYSTEM METHOD AND WORK SYSTEM THEORY}

Work system method. The development of WSM was motivated by the goal of creating a flexible system analysis and design method for use by business professionals for their own purposes and for joint use by business and IT professionals. The joint use would be part of the initial analysis for designing work system improvements that might or might not involve producing software. It also would support ongoing maintenance activities. The history of WSM is explained in [6] along with many citations as part of the background for explaining WST, which underlies all versions of WSM.

While details vary across different versions of WSM, the following guidelines apply in general.

- WSM starts by identifying the smallest work system that has the problem or opportunity that launched the analysis, typically starting by summarizing the work system using a function-oriented verb phrase, such as manufacturing chairs, selling refrigerators, or providing network support for employees.

- Tables of internal and external performance gaps related to costs, quality, speed, errors, and other important metrics clarify the nature of the problem.

- The "as is" work system is summarized using a "work system snapshot" (example in Table 2). 
- The analysis proceeds by drilling down to look at structure and issues related to the various elements of the work system framework and their interactions.

- Customer concerns and responsibilities are explained.

- Analysis techniques from general problem solving, Six Sigma, and other approaches are used as needed.

- A design phase identifies possible improvements and proposes specific improvements. The design phase may use one or more "design spaces" [7].

- The proposed "to be" work system is summarized using a work system snapshot, thereby clarifying differences between the "as is" and "to be" work system.

- The proposed changes are justified using any of a variety of rationales that may be relevant.

Definition of work system. A work system is a system in which human participants and/or machines perform processes and activities using information, technology, and other resources to produce products/services for internal or external customers. Enterprises that grow beyond a largely improvised start-up phase consist of multiple work systems. Work systems in typical business enterprises procure materials from suppliers, produce products, deliver products, find customers, create financial reports, hire employees, coordinate work across departments, and perform many other functions.

Special cases. There are a number of important special cases of work systems. Information systems are work systems all of whose activities are devoted to processing information. Projects are work systems designed to produce specific products/services and then go out of existence. Sociotechnical work systems have human participants, in contrast with totally automated work systems, which operate autonomously and automatically after being launched.

Three components of work system theory. As explained in depth in [6], WST is a perspective for thinking about systems in organizations in which the unit of analysis is the work system. WST consists of three components:

- the definition of the term work system

- the work system framework, a static view of a work system as it exists during a time interval

- the work system life cycle model (WSLC), a dynamic view of how a work system changes over time.

A number of extensions of WST have been developed to address a variety of issues related to describing, understanding, analyzing, designing, and improving work systems. An extension that is significant for current purposes is a work system metamodel (Fig. 1) that reinterprets the work system framework, creating a more detailed view of a work system that is more useful for systems analysis and design. Other extensions that are not directly relevant for the current discussion include work system design spaces [7], work system principles [8], rephrasing of the work system metamodel in relation to service systems, a theory of workarounds, a taxonomy of system interactions, an approach for incorporating more knowledge into systems analysis and design, and a proposal for using work system concepts to organize a body of knowledge for information systems.

\section{CENTRAL FRAMEWORKS IN WST}

The work system framework identifies nine elements in a basic understanding of the work system's form, function, and environment. Processes and activities, participants, information, and technologies are completely within the work system. Customers and products/services may be inside and/or outside because customers often participate in processes and activities within a work system and because products/services take shape within a work system; environment, infrastructure, and strategies are viewed as largely outside a work system even though they have direct effects within the work system.

Processes and activities. Activities are the action steps within a work system. A work system must contain at least one activity. Otherwise it does not do anything. Sequences of activities may be structured enough to be called processes.

Participants. Participants are people who perform work within the work system, including both users and non-users of IT. Participants are identified using actor roles, although their skills, knowledge, training, and incentives are evaluated based on the people who actually play those roles. Customers are often work system participants, especially in service systems.

Information. All work systems use or create information, which is expressed in this context as informational entities that are used, created, captured, transmitted, stored, retrieved, manipulated, updated, displayed, and/or deleted.

Technologies. Specification and details of technologies used often are unimportant in summarized descriptions of a work system's scope but are quite important for describing a work system's operation in depth. Technologies include both tools used by work system participants and automated agents.

Products/services. Work systems exist to produce things for their customers. The term products/services recognizes that outputs of most work systems combine product-like and service-like characteristics.

Customers. Customers are recipients of a work system's products/services for purposes other than performing work activities within the work system. An analysis of a work system should consider who the customers are, what they want, and how they use whatever the work system produces.

Environment. This includes the relevant organizational, cultural, competitive, technical, regulatory, and demographic environment within which the work system operates, and that affects its effectiveness and efficiency. Environment may have direct or indirect impacts on performance results, aspiration levels, goals, and requirements for change.

Infrastructure. This includes relevant human, information, and technical resources that are used by the work system but are managed outside of it and are shared with other work systems. From an organizational rather than a purely technical viewpoint, this includes human infrastructure, informational infrastructure, and technical infrastructure. 
Strategies. Strategies that are relevant to a work system include enterprise strategy, department strategy, and work system strategy. In general, strategies at those three levels should be in alignment, although that is not true in many cases.

\section{WORK SYSTEM LIFE CYCLE MODEL}

The work system life cycle model (WSLC) represents the iterative process through which work systems evolve over time via a combination of planned change (projects involving allocation of resources by management) and emergent (unplanned) change that occurs locally, often with no management involvement or awareness, through adaptations, local experimentation, and workarounds. Planned change occurs through projects that include initiation, development, and implementation phases. Development involves creation or acquisition of resources including hardware, software, documentation, and training materials. Implementation is the process of implementation in the organization rather the technical realization of detailed specifications. The WSLC treats emergent change as a natural part of the evolution of most work systems, implying that realistic engineering of enterprises should consider likely avenues for predictable emergent change. With its iterative nature and focus on work systems rather than software per se, the WSLC is fundamentally different from the SDLC, Rational Unified Process (RUP) and other IT-oriented process models that are designed to guide software development projects.

\section{WORK SYSTEM METAMODEL}

Fig. 1 is one of a number of versions of a work system metamodel that augments the work system framework. The work system framework helps in summarizing a work system and achieving mutual understanding of the scope and nature of a work system. It is less effective as a tool for detailed analysis.

The metamodel builds makes concepts in the work system framework clearer, more rigorous, and more useful for work system documentation and software development. This creates a bridge between summary level descriptions and more detailed models and subsystems during analysis and design. It does that without requiring the precision, terminology, and notation of BPMN or of rigorous software specifications. When used with a second layer that identifies common characteristics, metrics, and principles for specific elements, it can support traceability between a summary level analysis and more detailed analysis and documentation by IT specialists.

The metamodel is a more detailed re-interpretation of the elements of the work system framework. Information becomes informational entity, technology is divided into tools and automated agents, activities are performed by three types of actors, and so on. Representation decisions in the metamodel try to maximize understandability while revealing potential omissions from an analysis or design process.

Fig. 1 hides a large number of important attributes such as goals, characteristics, metrics, and principles that apply to specific elements and relationships in the metamodel. Analysts using the metamodel would consider and apply the hidden attributes while defining the problem or opportunity, evaluating the "as is" work system, and justifying proposed improvements that would appear in the "to be" work system.

In essence, the work system metamodel says the following:

- Enterprises consist of work systems.

- Work systems always contain at least one work system activity and may contain one or more business processes if activities are sufficiently interrelated.

- Work system activities use resources to produce one or more "products/services from activity" that may be used as a resource for subsequent work system activities and/or may add to a "product/service for a customer."

- Customer work systems create value for customers using "products/services for customers" produced by the work system. (A discussion of value creation and value co-creation is beyond the current scope.)

- The resources used by a work system activity may include human resources (participants), informational resources, the technological resources, and other resources, each with various specific types.

- Three types of actor roles may perform work system activities: automated agents, noncustomer participants, and customer participants.

- Work system activities that use human resources (participants) rely on characteristics such as knowledge and expertise, skills, capabilities, and motives.

- Technological resources may include tools that are used directly by participants (e.g., a car driven by a person) or automated agents that perform work autonomously after being launched (e.g., a search engine).

- Informational entities include transaction records, plans, forecasts, commitments, strategies, and so on.

- Other resources used in a work system activity may include physical entities, time, resources from the environment such as organizational culture, laws, standards, regulations, and policies, and so on.

- Both the focal work system and customer work system may interact with other work systems generating positive and/or negative impacts for any of them.

\section{WORK SYSTEM INTERPRETATION OF DEMO EXAMPLE}

This section summarizes the EU Rental example that was used in [1] to compare a DEMO specification to a BPMN specification of a standard situation used by OMG. The EU Rental scenario is as follows: "EU-Rent is a company that rents cars to persons, operating from geographically dispersed branches. The cars of EU-Rent are divided in car types (brands and models); for every car type there is a particular rental tariff per day. A car may be rented by a reservation in advance or by a 'walk-in' customer on the day of renting. A rental contract specifies the start and end dates of the rental, the cartype one wishes, the branch where the rental starts (called the pick-up branch), and the branch where the rental 


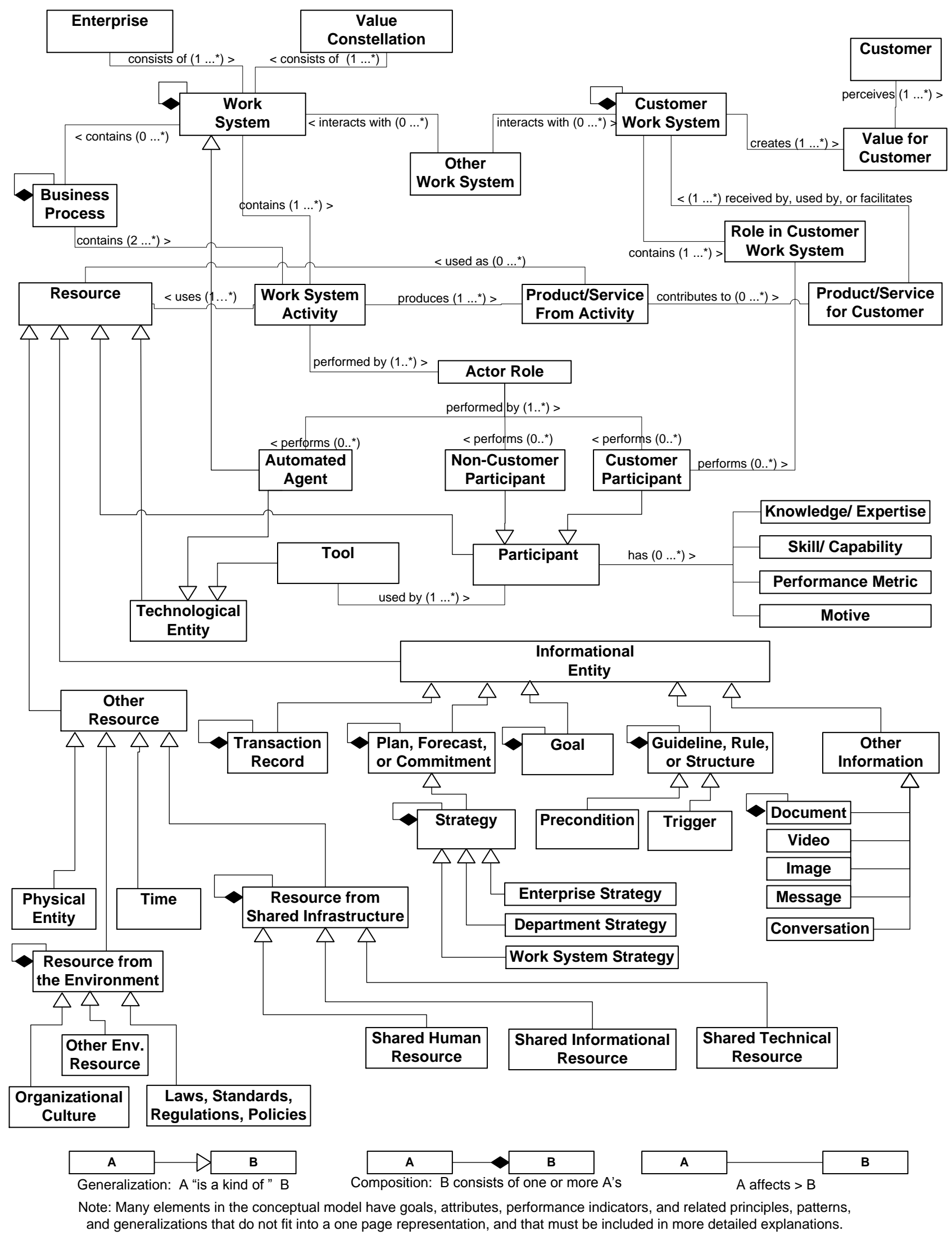

Fig.1. Metamodel for integrated analysis and design of sociotechnical and technical systems (revision of metamodel in [9]) 
will end (called the drop-off branch). Rentals have a maximum duration. The person who rents the car is called the renter. The one who is going to drive is called the driver. A rental will only be started if the driver has a valid driving license. In addition, a car of the requested type must be available. As soon as the car of a rental has been dropped-off, the rental can be ended, after the incurred charge has been paid. This charge may consist of several elements. First, there is the basic charge (number of days times the tariff per day). Next, there may be a penalty charge for exceeding this duration (number of extra days times the late return penalty tariff). Lastly, a location penalty charge is added if the car has been dropped-off at another branch than agreed (this charge depends on the distance between the branches)." [1, p. 82]

Table 1 identifies the transaction kinds and transaction results from the DEMO analysis of this situation [1 p. 83]. Fig. 3 is a DEMO construction model for EU-Rent.

Table 1. Transaction Result Table for the Test Case [1, P. 83]

\begin{tabular}{|l|l|}
\hline Transaction kind & Transaction result \\
\hline B-T01 rental start & B-R01 [rental] has been started \\
\hline B-T02 rental end & B-R02 [rental] has been ended \\
\hline B-T03 car pick-up & $\begin{array}{l}\text { B-R03 the car of [rental] has } \\
\text { been picked-up }\end{array}$ \\
\hline B-T04 car drop-off & $\begin{array}{l}\text { B-R04 the car of [rental] has } \\
\text { been dropped-off }\end{array}$ \\
\hline B-T05 rental payment & B-R05 [rental] has been paid \\
\hline
\end{tabular}

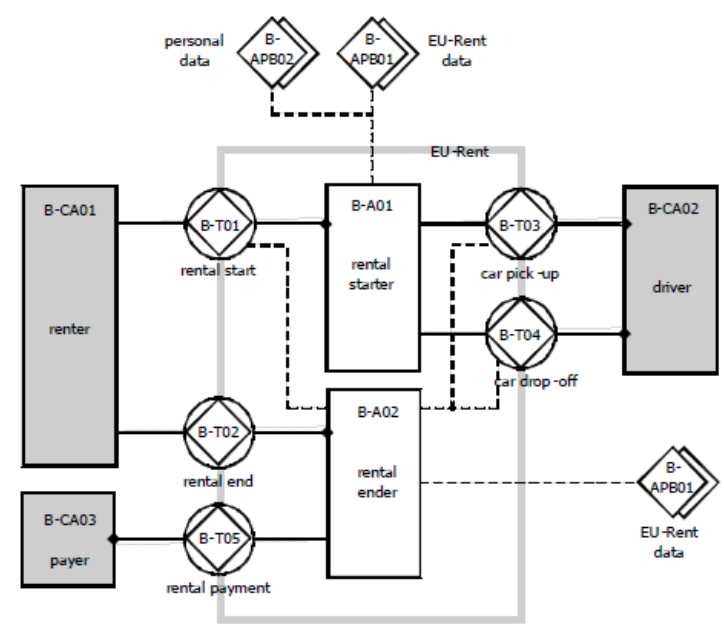

Fig. 3. Construction model of EU Rent [1, p. 84]

Comparing a work system representation with a DEMO specification demonstrates ways in which a typical work system description produces results that are similar to results from an analysis that uses DEMO. Important similarities and differences could lead to mutual synergies between DEMO and WST. Cross-fertilization of concepts and representations between DEMO to WST might help business professionals use the essence of DEMO without needing help from consultants.

\section{A. Work System Snapshot for the EU Rent Example}

Table 2 shows a "work system snapshot of the same situation. This type of diagram has been produced by many of hundreds of employed MBA and Executive MBA students as part of a classroom exercise of analyzing a problematic work system in their own organization and proposing improvements.

This work system snapshot includes the five transactions in Table 2, but it goes further than just listing the transactions.

Customers and products/activities. The work system exists to produce those products/services for those customers. To accommodate the DEMO example, payment for the rental is also included. Most work system snapshots produced to date have not included payments between the work system's providers and customers because payments related to internally directed products/services often occur in completely separate work systems. For example, service providers in an internal IT helpline are usually paid by the company's payroll system and not by employees who receive assistance from the helpline.

Processes and activities. This section of Table 2 describes the transactions using complete sentences that indicate the actor role that performed the activities. Notice that the first activity includes two actor roles, the rental agent and the renter.

Participants. Consistent with guidelines for work system snapshots, these are listed as actor roles, not as individual people. More detailed analysis of the work system certainly would look at the skills, knowledge, training, and incentives of the particular people who play those roles.

Information. Table 2 summarizes the information that is used or created. It includes some information that does not appear explicitly in the OMG BPMN specification or in the DEMO representation. For example it mentions the condition of the car upon drop-off, which the OMG specification addresses through an adjustment for a damaged car and which the DEMO construction model seems to subsume within the rental payment transaction.

Technologies. Consistent with DEMO, Table 2 says nothing about technologies because the essence of the work system is not about technologies. A typical work system snapshot would include several technologies that are relevant for analyzing the situation because specific technologies that are used often are part of the problem or opportunity.

\section{B. Summary of the EU Rent Example Based on the Work System Metamodel}

Table 3 is a more detailed summary of the situation based on the more detailed view of work system outlined by the work system metamodel. The same five transactions are included. Table 3 identifies the actor roles in a separate column. Information appears in two columns: information used, and information captured, created, updated, or deleted. That distinction is important operationally because information used is a resource that is an input to a specific work system activity, whereas the capture, creation, updating, or deletion of an informational entity is a product/service produced by a work system activity. Table 3 mentions the trigger that launches 
TABLE 2. WORK SYSTEM SNAPSHOT OF SITUATION DESCRIBED BY DEMO EXAMPLE IN [1, PP. 83-84]

\begin{tabular}{|c|c|c|c|}
\hline \multicolumn{2}{|c|}{ Customers } & \multicolumn{2}{|c|}{ Products/ Services } \\
\hline \multicolumn{2}{|l|}{$\begin{array}{ll}\text { - } & \text { Renter } \\
\text { - } & \text { Driver }\end{array}$} & \multicolumn{2}{|c|}{$\begin{array}{l}\text { For customers: } \\
\text { Rental of car consistent with rental contract } \\
\text { For providers: } \\
\text { Payment for rental }\end{array}$} \\
\hline \multicolumn{4}{|c|}{ Major Activities and Processes } \\
\hline \multicolumn{4}{|c|}{$\begin{array}{l}\text { - Renting agent starts rental through interaction with renter. } \\
\text { - Driver picks up the car. } \\
\text { - Driver drops off the car. } \\
\text { - Drop-off agent ends the rental. } \\
\text { - Renter pays for rental. }\end{array}$} \\
\hline Participants & & tion & Technologies \\
\hline $\begin{array}{l}\text { - Renting agent } \\
\text { - Renter } \\
\text { - Driver } \\
\text { - Drop-off agent }\end{array}$ & & $\begin{array}{l}\text {-up location } \\
\text { ant for payment, pick-up } \\
\text { late, end date, type of car, } \\
\text { arrangement for fuel in } \\
\text {-off }\end{array}$ & - $\quad($ not specified $)$ \\
\hline
\end{tabular}

TABLE 3. SUMMARY OF DEMO EXAMPLE USING CONCEPTS FROM THE WORK SYSTEM METAMODEL IN FIG. 3.

\begin{tabular}{|c|c|c|c|c|c|c|c|}
\hline Activity & $\begin{array}{l}\text { Actor } \\
\text { Roles }\end{array}$ & $\begin{array}{l}\text { Information } \\
\text { used }\end{array}$ & $\begin{array}{l}\text { Information } \\
\text { captured, } \\
\text { created, } \\
\text { updated, or } \\
\text { deleted }\end{array}$ & Trigger & Preconditions & Business rules & $\begin{array}{l}\text { Post conditions } \\
\text { (including } \\
\text { products/ } \\
\text { services } \\
\text { produced) }\end{array}$ \\
\hline $\begin{array}{l}\text { Renting } \\
\text { agent } \\
\text { starts } \\
\text { rental } \\
\text { through } \\
\text { interaction } \\
\text { with } \\
\text { renter. }\end{array}$ & $\begin{array}{l}\text { - Renting } \\
\text { agent } \\
\text { - Renter }\end{array}$ & $\begin{array}{l}\text { - Availability of } \\
\text { cars } \\
\text { - Renter's } \\
\text { credit card or } \\
\text { other payment } \\
\text { capability } \\
\text { - Driver's } \\
\text { license of } \\
\text { driver } \\
\end{array}$ & $\begin{array}{l}\text { - Rental } \\
\text { contract }\end{array}$ & $\begin{array}{l}\text { - Request } \\
\text { for rental } \\
\text { from renter }\end{array}$ & $\begin{array}{l}\text { - Driver has } \\
\quad \text { valid } \\
\text { driver's } \\
\text { license }\end{array}$ & $\begin{array}{l}\text { Rent only if the } \\
\text { driver has a valid } \\
\text { driver's license. }\end{array}$ & $\begin{array}{l}\text { - Car rented and } \\
\text { available for } \\
\text { driver's use }\end{array}$ \\
\hline $\begin{array}{l}\text { Driver } \\
\text { picks up } \\
\text { the car. }\end{array}$ & - Driver & $\begin{array}{l}\text { - Rental } \\
\text { contract }\end{array}$ & $\begin{array}{l}\text { - Car picked } \\
\text { up }\end{array}$ & $\begin{array}{l}- \text { Car rented } \\
\text { and } \\
\text { available } \\
\text { for driver's } \\
\text { use } \\
\end{array}$ & $\begin{array}{l}\text { - Car rented } \\
\text { and } \\
\text { available for } \\
\text { driver's use }\end{array}$ & $\begin{array}{l}\text { Permission to } \\
\text { leave EU Rent } \\
\text { location with car } \\
\text { only if rental } \\
\text { agreement exists. }\end{array}$ & $\begin{array}{l}\text { - Departure of } \\
\text { driver from EU } \\
\text { Rent pick-up } \\
\text { location }\end{array}$ \\
\hline $\begin{array}{l}\text { Driver } \\
\text { drops off } \\
\text { the car. }\end{array}$ & - Driver & $\begin{array}{l}\text { - Location of } \\
\text { drop-off site }\end{array}$ & $\bullet$ & $\begin{array}{l}\text { Driver is } \\
\text { ready to } \\
\text { drop-off } \\
\text { the car. }\end{array}$ & $\begin{array}{l}\text { Driver is } \\
\text { ready to } \\
\text { drop-off the } \\
\text { car. }\end{array}$ & $\begin{array}{l}\text { Drop off the car } \\
\text { at a branch of EU } \\
\text { Rent, not } \\
\text { elsewhere. }\end{array}$ & $\begin{array}{l}\text { - Car returned to } \\
\text { EU Rent. }\end{array}$ \\
\hline $\begin{array}{l}\text { Drop-off } \\
\text { agent ends } \\
\text { the rental. }\end{array}$ & $\begin{array}{l}\text { - Drop-off } \\
\text { agent }\end{array}$ & $\begin{array}{l}\text { - Rental } \\
\text { contract } \\
\text { - Condition of } \\
\text { car }\end{array}$ & $\begin{array}{l}\text { Drop-off } \\
\text { date, time, } \\
\text { and place } \\
\text { - Mileage } \\
\text { driven } \\
\text { - Condition of } \\
\text { car }\end{array}$ & $\begin{array}{l}\text { - Car } \\
\text { dropped } \\
\text { off }\end{array}$ & $\begin{array}{l}\text { - Car dropped } \\
\text { off }\end{array}$ & $\begin{array}{l}\text { - Adjust rental } \\
\text { charges based on } \\
\text { conformance } \\
\text { with rental } \\
\text { contract. }\end{array}$ & $\begin{array}{l}- \text { Rental } \\
\text { terminated. }\end{array}$ \\
\hline $\begin{array}{l}\text { Renter } \\
\text { pays for } \\
\text { rental. }\end{array}$ & - Renter & $\begin{array}{l}\text { - } \text { Rental } \\
\text { contract } \\
\text { - Location of } \\
\text { return } \\
\text { - Time and date } \\
\text { of return } \\
\text { - Condition of } \\
\text { the car at } \\
\text { drop-off }\end{array}$ & $\begin{array}{l}\text { - Date and } \\
\text { time of the } \\
\text { drop-off } \\
\text { - Condition of } \\
\text { the car }\end{array}$ & - Drop-off & $\begin{array}{l}\text { - Valid rental } \\
\text { contract }\end{array}$ & $\begin{array}{l}\text { - Renter pays in } \\
\text { accordance with } \\
\text { tariff from rental } \\
\text { contract. }\end{array}$ & $\begin{array}{l}\text { - Fulfillment of } \\
\text { renter's part of } \\
\text { the rental } \\
\text { contract. }\end{array}$ \\
\hline
\end{tabular}


each activity, the preconditions before the activity can occur, the business rules that are used in performing the activity, and the post-conditions after the activity is executed.

The differences between the work system snapshot and the summary based on the metamodel illustrate the reasons for using both tools. The snapshot helps in discussing the scope of the work system that has the problem or opportunity, but is not as good for going into more depth, understanding operational details and related issues, and designing work system improvements that might involve changes in any work system element. In conjunction with a series of work system design spaces [7] the work system metamodel provides better support for that effort. Illustrating that type of support, Table 3, includes specifics such as triggers, preconditions, business rules, and post-conditions. The work system design spaces provide organized access to work system principles, typical types of changes in work systems, important but changeable characteristics of work systems, and typical risks and obstacles. Table 3 might have included other columns based on the many entity types in Fig. 3. The columns in Table 3 were chosen for inclusion because most of them are the same concepts that are mentioned in [1, pp, 83-84], i.e., transaction, actor role, information, business rule, and states (pre-and post-conditions).

\section{Direct Implications}

DEMO and WST/WSM were developed for different purposes and started with very different premises, yet modeling of the same situation produces relatively similar results. WST/WSM summaries in Table 2 and Table 3 were produced without extensive grounding in DEMO's precise ontological underpinnings. An expert in DEMO might be able to create guidelines for work system snapshots and/or summaries based on the work system metamodel that would produce some of the same results as a complete DEMO analysis. Those guidelines might explain how to identify essential transactions, thereby making the processes and activities section of the snapshot more effective than many previous work system snapshots.

There are many possible benefits of a deeper exploration of overlaps and possible links between DEMO and WST/WSM concepts and methods. For example, use of concepts and methods related to WST/WSM might make some of the ideas in DEMO more accessible and usable with or without the help of DEMO experts or other consultants.

\section{DOES WST/WSM FIT DEMO's PHILOSOPHICAL UNDERPINNINGS AND INTENTIONS ?}

Synergy between WST/WSM and DEMO will be easier to achieve if there is substantial fit between their underpinnings and intentions. This section looks at whether WST/WSM fits with the enterprise engineering manifesto [4] and the fundamentals of enterprise engineering has proposed in [5].

\section{A. Fit Related to an Enterprise Engineering Manifesto.}

This section considers each of the seven postulates from [4]. Each postulate (P1 through P7) is restated in a brief form.

P1: Enterprises should operate as a unified and integrated whole. The metamodel says that enterprises consist of at least one work system. The rest of the metamodel outlines relationships within and between work systems.

P2: Enterprises are essentially social systems with roles and responsibilities. The metamodel identifies actor roles performed by human participants whose responsibilities include performing those roles and otherwise supporting the goals of the enterprise. Several extensions of WST/WSM raise questions about whether those roles and responsibilities will be played wholeheartedly, however, as when system participants create workarounds primarily for their own benefit. Realistic enterprise engineering efforts should produce engineering artifacts that address the possibility that various types of workarounds will occur for various repetitive types of reasons.

P3: Distinction between functional (black-box) perspective describing the essence of an enterprise versus construction (white-box) perspective describing the operation of enterprise. The processes and activities section of a snapshot can summarize the transactions (functions) that express the essence of the enterprise. The snapshot is an initial step from a function view toward a white-box construction model. The work system metamodel outlines some of the entity types in a white-box construction model and can be used as the basis of decomposing a work system to various levels of detail.

P4: Need to start with a constructional design of the system (with its ontological model) in order to manage its complexity. WST/WSM provides an ontological model that can support the constructional design of the work system, but does not insist on doing the work in a particular order. Instead, WSM assumes that WSM users will iterate between initial understandings, deeper realizations, and clarification of earlier parts of the analysis as their understanding solidifies.

P5. Need for people to be able to internalize the ontological model of the enterprise. WST/WSM is based on a similar assumption that business professionals need organized ways to think about systems in their own organizations (e.g., $[6,10])$. Providing organized methods and tools applies the ontological approach expressed in WST and its extensions.

P6. Operational compliance with strategic concerns of the enterprise requires functional and constructional normative principles that constitute an enterprise architecture. WST/WSM provides a path toward producing an enterprise architecture because an enterprise consists of multiple work systems that can be described, analyzed, decomposed, and changed at different levels of detail.

P7. Governance is needed to achieve and maintain unity and integration in the development and operation of the enterprise. WST/WSM assumes that enterprises consist of multiple work systems, but the unit of analysis is the work system, not the enterprise. Governance is a set of work systems whose products/services constitute governance. Thus, WST/WSM makes it possible to describe and analyze governance like any other function within an enterprise.

\section{B. Fit Related to Enterprise Engineering Fundamentals}

Since DEMO fits 7 enterprise engineering "fundamentals" proposed by [5], we explore whether WST/WSM fits those same fundamentals (numbered below as F1 through F7). 
F1: strict distinction between function and construction. Table 2 showed that the representation of function in a DEMO example could be expressed as processes and activities in a work system snapshot. The more detailed view in Table 3 is about construction, evaluation and design. Past uses of WSM have included many examples in which an initial description of function was changed later based on new understandings from analyzing the work system's construction details.

F2: focus on essential transactions and actors. A work system snapshot includes transactions and actors. WST/WSM provides concepts and methods for describing an organization as a transaction-based organization [11]. An area of possible synergy between WST/WSM and DEMO is in guidelines for identifying essential transactions and clarifying the importance of non-essential (in the DEMO sense) activities that are still part of the operation of an enterprise.

DEMO and WST/WSM both assume that actors perform all activities. An important difference is the explicit possibility in WSM/WST that actor roles may be performed by nonhuman automated agents. Inclusion of automated agents is necessary for creating construction models of work systems that rely heavily on computerized capabilities.

F3: rigorous distinction between design and implementation. The typical sequence for using WSM starts by focusing on function and summarizing how well function is performed. For example, Table 2 illustrates that WST/WSM allows but does not require specificity about particular technologies that are used. The analysis looks at implementation details and performance data in more depth, leading to designing potential improvements. A set of "design spaces" may be used to support design activities. [7].

F4: diligent application of design principles. WST/WSM supports the use of design principles but does not require their use. An extension of the WST is a set of 24 work system principles that apply to work systems in general [8]. The enterprise, department, and work system strategies in the metamodel provide a place holder for situation-specific design principles that can be used during the initiation phase of the WSLC. Note, however, that strategies in many organizations are unclear and/or inconsistent with reality.

F5: distributed operational responsibility. WSM tries to empower business professionals to understand work systems and to have analysis-based views related to evaluating and improving work systems in their own organizations $[6,10]$. Details of WST say nothing about whether operational responsibilities should be centralized or distributed. It assumes that providing a genuinely usable language for talking about systems in organizations will help owners, managers, and employees decide how to organize work for mutual benefit.

F6: distributed governance responsibility. As with F5, the details of WST/WSM say nothing about whether governance responsibility should be distributed. WST/WSM treats governance is a separate work system that can be defined as specific actor roles performing specific processes and activities for particular purposes.

F7: human-centered and knowledgeable management. The goal of WST/WSM is to provide a systems analysis method that business professionals can use for their own purposes, with or without consultants and IT professionals. Empowerment by an organized, effective way to understand systems in their own organizations would help managers and business professionals succeed in their own work and would help them coordinate with business peers, executives, IT experts, and vendors.

\section{CONCLUSION OF AN INITIAL EXPLORATION}

This paper demonstrated that a work system perspective on enterprise engineering articulates with Dietz's DEMO method, thereby potentially leading to synergies between the two approaches. An example illustrating DEMO was expressed based on WST, and WST provided a way to describe both a functional view that deemphasizes operational details and a construction view that clarifies many details. Ultimately, WST and the work system metamodel provide a form of traceability between functional and construction representations of work systems and their subsystems at various levels of detail.

This first step in studying relationships and potential synergies between DEMO and WST/WSM showed that the fit is close enough to justify further analysis. Follow-on steps should look at additional DEMO examples, focusing on the transaction result tables, construction models, and other available documentation. WST/WSM might provide an avenue for making DEMO more accessible and usable by business professionals. The rigorous underpinnings of DEMO could provide guidelines for producing essential models of work systems that might lead to improved versions of WSM and possibly to new or improved extensions of WST.

\section{REFERENCES}

[1] M. Op't Land and J. L. G. Dietz, "Benefits of enterprise ontology in governing complex enterprise transformations." In Advances in Enterprise Engineering VI, pp. 77-92. Springer Berlin Heidelberg, 2012.

[2] OMG: Semantics of Business Vocabulary and Business Rules (SBVR), v1.0, 2008 .

[3] OMG: Business Motivation Model, v1.0, 2008.

[4] J. L. G. Dietz (ed.), "Enterprise Engineering Manifesto, Jan. 2011, http://ciaonetwork.org/publications/EEManifesto.pdf.

[5] J. L. G. Dietz et al., "The discipline of enterprise engineering," International Journal of Organisational Design and Engineering, 3(1), 2013, pp. 86-114.

[6] S. Alter, "Work System Theory: Overview of Core Concepts, Extensions, and Challenges for the Future," Journal of the Association for Information Systems, 14(2), 2013, .pp. 72-121.

[7] S. Alter, "Work Systems as the Core of the Design Space for Organizational Design and Engineering," International Journal of Organisational Design and Engineering, 1(1/2), 2010, pp. 5-28.

[8] S. Alter and R. Wright, "Validating Work System Principles for Use in Systems Analysis and Design," Proceedings of ICIS 2010, the 31st International Conference on Information Systems.

[9] S. Alter, "From Resources and Activities to Value for Customers within Systems of Service Systems," Proceedings of SIG-SVC 2013 Workshop, Dec. 15, 2013, Milan Italy

[10] D. Truex, S. Alter, and C. Long, "Systems Analysis for Everyone Else: Empowering Business Professionals through a Systems Analysis Method that Fits Their Needs," Proceedings of ECIS 2010.

[11] J. L. G. Dietz and J. A. P. Hoogervorst, "The Principles of Enterprise Engineering."Advances in Enterprise Engineering VI. Springer Berlin Heidelberg, 2012, pp. 15-30. 